\title{
THE HELP OF THE TEACHER IN THE MEDICAL INSPECTION OF SCHOOL CHILDREN.
}

\author{
By W. IJIOYD EDWARDS, D.P.H., \\ School Medical Offices, Barry.
}

(MEMBIR.)

\begin{abstract}
$A^{T}$ the beginning of this year the medical inspection of school children A became one of the compulsory duties of all local Education Authorities. Hitherto, whilst a large number of Education Authorities had provided for medical inspection of schools, the sanitary condition of the building, etc., the regular systematic examination of each scholar hatd not bcen arranged to any great extent.

In this, we were far hehind most other cirilized countries. In Brussels a system of medicil inspection was instituted about twenty-five years ago, and in one of the special reports on educational subjects, a full account is given of the procecture, the rhilleen even heing given an iron tonic mixture from a lirge bottle.
\end{abstract}

In Iapan they have organised the medical rxamination very thoroughly, whilst in Germany a recent pamphlet published by our Board of Education states that they "latre systematised the medieal inspertion of the primary sehouls buyond any other country."

In Hungary th." soliool medical inspertion hats been taken very seriously, and no medical man is allowed to commence duties until he has attended a three-anci-a-half months' course of special instruction in school medical inspection. Many of the larger cities of America have also organised the medical inspection of schools on a very complete scale.

Whilst, therefore, we have the benefit ancl experience of the work in other countries, thuse medical men who have now taken on those duties in consequence of the Education Act, 1907, have to work out many problems and details with but little past experience to gruile them. Perhaps I ought to except the splendid record of work dome for the London County Council by the Medical Officers of Education as shown in the five aunual reports by Dr. Kerr.

One of the main problems has been how much can or ought we to expect the teachers to help in the work. During the discussions prior to 
the passing of the Act there were some who strongly opposed any Act making the merlical inspection of school children compulsory, until a new generation of teachers harl come into the schowls who had been thoroughly trained in hygiene. Doubtless such a training is highly important, and one is gratified at hearing that the Board of Education intend making hygiene one of the subjects for training college instruction; lut it must he remembered that now, for many years past, teachers have had some knowledge of hygienc. Recognising its importance they attended South Kensington Science Courses in Physiology and Hygiene, and, indeed, especially among the girls, by means of Readers and in Domestic Economy teaching, some amount of hygiene has been taught in the schools. I think all this proves that the teachers are as a rule competent to give valuable assistance in the matter of school inspection. 'They are fully aware of the immense importance of the physical condition of the child and its bearing on its progress in school, and the teaching profession hats everywhere welcomed medical inspection, as tending to aid materially in their vork. In Germany "many teachers from the first heartily greeted the schoul doctor as a co-worker, whose functions well supplemented and supported their own, and suspecting no necessity for jealousy and friction found none. Others regarded the school doctor not as a colleague, but as a rival, and viewed his coming with distrust."

With regard to this, the same pamphlet, "School Doctors in Germany," from which I have just quoted, states that Dr. Sichubert, a well-known authority on this subject, is of opinion that the strongest opposition comes from these teachers who have no sohool doctor in the locality. and are only expressing the feal of the miknown.

Dr. Leslie Mackenzie, Merlical Member of the Lucal Government Board of Scotland, said in a paper read before the last International Congress of School Hygienc, "that he found that the teachers have taken to medical inspection with enthusiasm. They were in Scotland the chief promoters of the movement. They have in many places welcomed expositions of what the proposed inspertion implies. In one or two places where a medical officer of schools has been appointed, they have offered him the most cordial assistance. Recently the school teachers of Glasgow collected a vast number of observations on the height, weight, and physical conditions of the rhildren. In Edinburgh, the medical officer of schools has, with the cordial co-operation of the teachers, curried through a preliminary enquiry into the acuteness of vision of the school children." "Everywhere the report is that the teachers find the work full of interest." The teacher is able to provide essential details as to age, 
occupation of parents, size of house, reginlarity of attendance, hour's of rest and work. He can also record height and weight. It is easy to see that the teacher is at every stage of the child's school life an inclispensalile and reliable coadjutor in medical inspection. Above all, he is in constant touch with the parent.

We may therefore be well assured that the teachers as a whole will sladly welcome and co-operate with the medical officer. But if we call count on their ready and willing help, one must consider how much additional work it is fair to place upon the teacher. Only those who have spent much time in the schools, can realise the multitudinous duties which devolve upon the head teacher. Besides the usual school work, and examination of classes, there are numerous interviews with parents, attendance officers, etc. We must therefore be particularly careful not to give them too much to do, though a good deal of their help is indispensable. Though I have only recently commenced my duties as a school medical officer, I can at least claim a thorough knowledge of the sehools, teachers, and scholars, having for many long years been intimately associated with the growth of the educational system of Bary, as a member and also as Chairman of the School Board. It may therefore be of interest to give $m y$ experience as to the help the teachers have given me in my work.

First of all it is only right to state that, compared with many places, the teachers are working under favourable conditions. According to a Buard of Elucation return the classes are smaller in Bary than in almost any other district, there being $26 \cdot 6$ certificated teachers to every 1,0011 children, which, with the exception of Hornsey, is not exceeded by any other place in England and Wrales.

It would not, therefore, be fair to expect so much from the teachers of other districts, where pussibly they may have very large classes and overcrowded buildings. In starting the system of medical inspection I first of all met the head teachers in conference, and explained to them the requirements of the Board of Education. These were of a minimum amount, and the schedule of the Board has been adopted in its entirety with onc or two modifications.

I explained that as the examination of each child would practically le trieunial (at entrance, at the ages of seven and ten years ancl at learing), such details as height and weight would be of scarcely any value if taken only once in three years. In Germany, the height and weight are taken every six montlss, and an annual weighing and measuring of each child was necessary if any useful information was to be lerived as to physical development. But such annual data could not be obtained by the school 
medical officer mless each teacher took them for his own class. The opinion of the head teachers was in favour of doing this work annually, so that even in the first year I hope to have every child in the Barry Schools both weighed and measured. Some of the teachers had already been taking the height of the boys in connection with the annual athletic sports, which I am glarl to say have been very successfully and enthusiastically worked by the teachers. At my first visit to one of the boys' schnols I fouml that the older boys, while at the educational handwork centre, had made a most elaborate measuring standard, all complete with platform and scale in inchrs and centimetres properly marker. This indeerl was co-operation.

The procedure adopted is as follows:- Two cards are given for each child in a class, the duplicate one being for the central office. On this the class teacher, or, in the case of older children, the rhild himself, writes:-Name and ardlress; name of school; clate of birth; and also height and weight in centimetres and kilograms. Once a year also the class teacher will enter on this card the possible and actual attendances of the child. This will be al comparatively easy matter, as these attendances have alrearly to be looked up on the register for the attendance prizes which are awarded annually. Indeed, these cards will in the future do away with the necessity of hunting up a lot of oll registers in the case of children who have made an unbroken attendance for seven years, and so obtained a special prize, and these are by no means uncommon. I regard the actual attendance of the child as being a very important record. Fuealing broadly, there are only two main factors in bad attendance, bad home conditions, careless parents, etc.; so that the actual attendances will in after years be of great use to the school medical officer in estimating the physical status of the child. At Barry, hefore the actual examination is held a circular is sent out to all the parents explaining the new Act as regards medical inspection, and inviting them to return a card with a schedule of diseases, filling in which the child has had, and whether before or after admission to school. These carls, on their return, are stored for the medical officer to copy on to the proper column on the nedieal inspection card. I am glad to say that the teachers hale succeeded in nearly every case in having the card back from the parents. One headmaster told me on my visit of inspection to his school that every card had heen returned. The information gained will be valuable. Already from a glance at these carls I am surprised at the number of children who are reported to have had measles and whooping congh before their entrance into school. However, I have not had time 


\section{8:2 Hely of T'achers in Merlical Insprertion of Srhoul Children.}

to obtain any actual statistics on this point, but I can see that such information will be of importance in regard to the question as to whether children should enter school before five or not.

Of course, the medical inspection finds every child, warned beforehand, ready for the doctor with "shining morning face," so that, in recording the state of the body as regards cleanliness, clothing, etc., it is the teacher who can give a really accurate estimate. It is the same with regard to the mental condition of the child. Whilst the personal observation of the school doctor soon becomes a fairly accurate one, it is always well to know the teacher's opinion, as he has had long and continuous chances of estimating; and, besides, is trained for that work.

At Barry each school has a vision-testing register, which hitherto has been filled up by the teachers. After this year the school medical officer will be able to do the vision-testing himself; but at present, whilst he tests the rision of all children medically examined this year (except, of course, the roung infants), it would be impossible to test every child. I find, however, that the teachers who have been dloing this for some years rather like the work, and in cases of defect draw my attention to the errors. Where any eye defects are discovered a coloured card is sent to the parent with advice as to the proper procedure.

There are also similar cards of various colours for all the more usual defects, such as adenoids, bad teeth, deafness, etc.

At first sight all this seems a lot of work to the teacher, but after the first year the work will be very slight, as each child will be examined only about once in three years. The trouble is well worth taking if the teacher can manage it. Just as in the scheme of schoul work the subjects are now all correlated, we shall find the inter-dependence of the school doctor with the school teacher; and one speedy result of medical inspection ought to be the throwing more light on the dark places in our educational system. The huge classes we find in some schools are perfectly absurd. With them there can be no individual attention, and, what is so important for the teacher, there can be but little knowledge of each child's nature, and allowances for each little individnal's idiosy'ncracies.

Then again the overcrowding in our primary schools is very great. The space of ten square feet per child prescribed by the building rules of the Board of Education is itself far too small, but even this is sometimes reduced in practice. I have seen new and beautiful buildings with classrooms empty and an adjoining one fearfully overcrowded with children-all owing to the fact that one teacher could not be in the two class-rooms at the same time. 
Let us hope that the advent of the school medical officer will at least tend to make the burden of the teacher's life lighter. I have briefly sketched in this short paper what could be considered the amount of help which ought to be expected, and as all are working for a common object I do not think that school medical officers, provided they have tact and due consideration for the teachers, will ever find lacking that hearty zeal and co-operation on the part of the teacher which alone can make this work of lasting benefit to the children.

\section{[This Discussion applies also to the Paper by Dr. C. J. Тномas, prige " $\% 6 \%$.]}

Dr. H. MLreditu Richinds (Croydon) emphasized the readiness with which teachers would co-operate in the work of the medical officer, and the importance of reducing clerical work to the smallest possible dimensions. The school nurse, too, could lighten the work.

In Dr. Thomas's paper he was most interested in the proposed auxiliary classes which met a very real want in our educational system. In his own district they had initiated such a class in commection with a small group of schools. To this class, wbich would be limited to twelve, children, boys and girls, would be admitted after eximination by the inspector and medical officer. It was intended to reserve the class for children who would eventually be transferred to the ordinary school, or at any rate be educated by the special methods of the class into normal citizens. The mentally defective child was best provided for in residential schools and subsequent colnnies.

Miss C. Cochrane (St. Neots) said that dull but not mentally deficient children should be allowed to leave school at the same age as others in the school. Prolonged attendance did not render them more fit to follow their vocation in after life, especially if this was agricultural.

Elder girls and infants should be examined by medical women.

Attendance of cbildren who were between five and six years should be optional.

Miss Monris (West Riding C.C.) urged the willingness of many teachers to co-operate in anything which was for the welfare of the child. Iome conditions were not ideal in many cases, aud the prospect of having pressure brought to bear on parents to bave the health of children attended to would generally be welcomed.

In districts where the system of halt-timers still obtained, it was often found to make too great demands on the children, and especially where conditions of ventilation, etc., were defective, it becomes a matter of question whether beneficial, either physically or mentally. 


\section{Tht Help of Teacher's in Medical Inspertion of Sthonl Children.}

Mr. T. W. Berry (Rhondda) adrocated the formation of auxiliary classes, but the whole question was one of finance, as was also the question of increased floor space. He deprecated on social, mental, physical and economic grounds the half-time system of schooling. With regard to mentally defective and slow children, educational handicraft was the remedy if followed by the formation of mentally defective colonies and agricultural training. Teachers were keenly in sympathy with the medical inspection of schools, hut they strongly opposed the idea of this constantly increasing clerical work. Teachers wore trained to teach, and to utilise them in side issues was economically and educationally unsound.

Dr. Widuams (Flintshire (.C.) questioned how lar it was advicable for teachers to do the clerical work in connection with the medical inspection of children. Their duty was to tench, and this was necessary and their time for teaching ouglit not to be curtailed. Again, what was the best method specially for the rural district as to merlical inspection, whether the local medical men world not be able to do the work best, as they linew the home life of the parents and children, and could see as to the carrying out of treatment.

Dr. J. F. McFanex (Govan) said the teachers gave him very learty co-operation in the diweharge of his work as medical inspector.

Intervipws with parents were requested in the cases where defects wore discovered. The response was very satisfactory.

Mentally and physically defective children wer' taught in separate schonls. They wre taught according to their capacity. Thur lives were made as loright and comfortable as possible. They were taken to and from their homes to the school in very connfortable vans.

Mn. A. W. Swash (Cardiff) said that he should be excedingly sorry if there was any general impression among the audiences that teachers were opposed to medical inspection of school children. On the contrary, the matter had been discussed very carefully in Cardiff, and the whole desire amongst the profession was to assist in so useful and praisewortlyy an object. But the teacher was fundamentnlly in existence to impart linowledge, and he could only spare a certain amount of time without interfering with the actual teaching work. So far as opportunity allowed they would second the efforts of the medical officer to the very utmost of their ability. No subject was so important as ventilation, yet he felt the Board of Fducation did not insist on a sufficient amount of fresh air being supplied even in the newer schools. Teachers pressed for more rentilators, the Board of Education inspector was sympathetic, but Education Committees and Managers evaded their responsililitirs.

Dr. J. R. Kaye, Miss A. Ratexilut, Dr. C. J. Thomas, and Dr. Ltovid Edwarns also took part in the discussion. 